\title{
PNF in Practice - An Illustrated Guide
}

\section{2nd revised edition}

Springer-Verlag

Susan S Adler, Dominiek Beckers,

Math Buck

B ooks on PNF tend to be very technical, but I was pleasantly surprised when reviewing this book. It is easy to follow with plenty of illustrations to assist the reader in understanding the text. The authors have emphasised that it is a practical techniques book using visual aids rather than words to describe actions. I did find that it had little theory, and as suggested, further reading is necessary in this area for postgraduates. Certainly this book is more than adequate for undergraduates and for the generalist who wants to have a reference book handy. It has all the basics - principles, special techniques (not all - I felt timing for emphasis was not comprehensively explained), upper and lower limb patterns, neck and trunk patterns and face patterns. It gives good alternate staring positions with both new and old terminology. I found that it not only incorporated both upper and lower limb patterns with mat work (alternate positions) and special techniques, but also listed all the muscles used in a particular pattern. I find the presentation encouraging as generally students have difficulty in integrating different concepts. I was also pleased to see that precautions were specially mentioned in block form.

I have a major concern that this book lacks an index of subject matter. I would however definitely recommend this book to the undergraduate and the qualified generalist.

\section{Jessico Lund}

